\title{
Der Preis und sein Stifter
}

Erhard Taverna

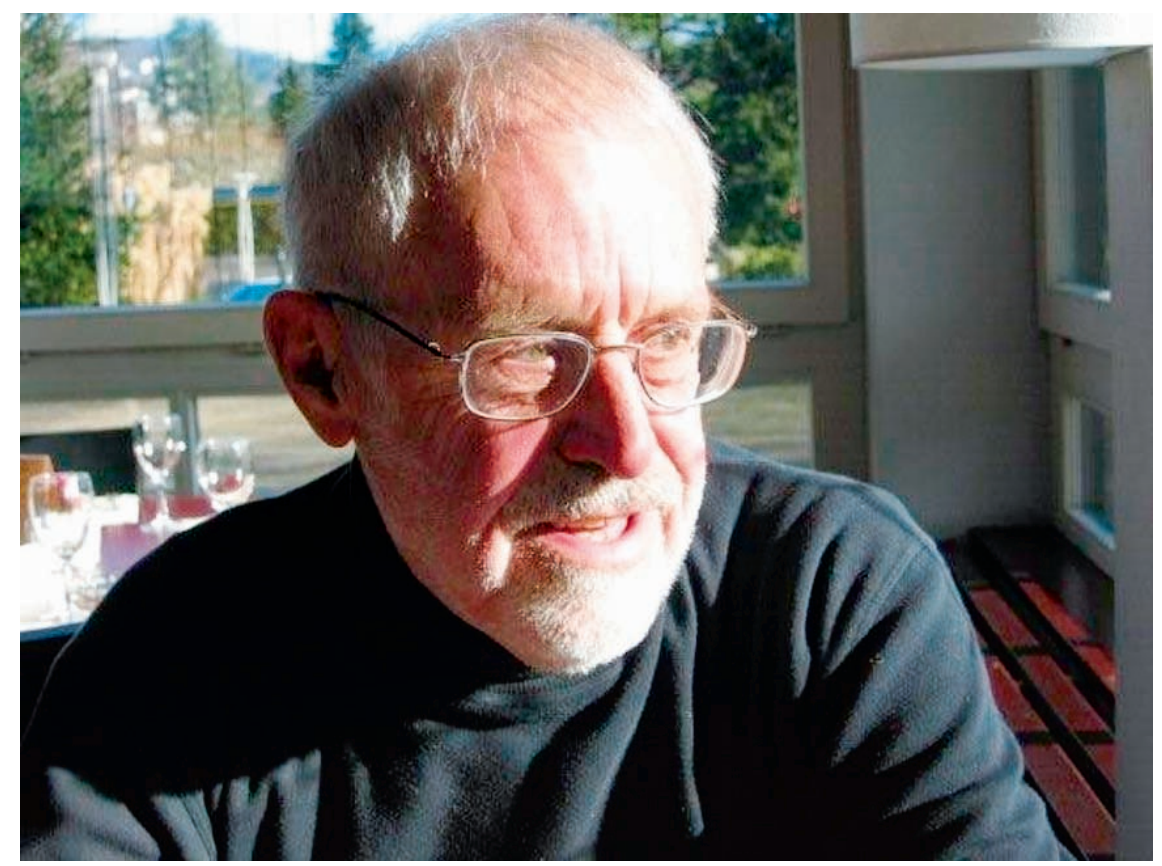

Initiant und privater Geldgeber ist der 1929 geborene Alfred M. Debrunner, Sohn von Hans Debrunner, langjähriger Chef der orthopädischen Abteilung am Triemlispital mit einer Privatpraxis in Zürich bis 2002. Sein Sohn und Kardiologe Johann Debrunner wird den Vater in der vom Professor für Hausarztmedizin Dr. med. Peter Tschudi aus Basel präsidierten Jury vertreten. Alfred M. Debrunner hat selbst ein Lehrbuch für Orthopädie geschaffen, dessen vierte und vollständig überarbeitete Auflage 2003 mit dem süddeutschen Carl-Rabl-Preis ausgezeichnet wurde. Dieses Standardwerk zur Diagnostik und Therapie des Bewegungsapparates, dessen 5. Auflage vorbereitet wird, setzt Massstäbe, denen zu genügen nicht leicht sein wird. Der Prix Debrunner möchte mithelfen, aus der täglichen Nachrichtenflut das Wesentliche, Bewährte und Praktische für die Anwendung in der Praxis herauszufiltern. Weil beim ersten Arztbesuch die orthopädischen Krankheiten am häufigsten vorkommen, sollen die aktuellen Grundlagen und Prinzipien zuverlässig in ein Raster von Basiswissen eingeordnet werden. Das Logo der Brücke steht für die Zusammenarbeit von Spezialist und Hausarzt zum Vorteil der gemeinsamen Patienten. Alfred Debrunner ist sich bewusst, dass er gegen den Strom schwimmt. Der Wissenstransfer von der Spitze zur Basis ist wenig prestigebringend und deshalb nicht populär. Dem akademischen Ansehen sind der Zitationsindex und die meist industriegesponserten Preise förderlicher, auch wenn der eigene Aufwand nicht immer der Ehrung entspricht. Der neue Preis ist als Gegengewicht gedacht, als Ansporn für den Lehrer und praktischen Arzt, der nicht wegen seiner telegenen Spitzenmedizin im Rampenlicht steht. Im anschwellenden Wettbewerb der Spitäler und Praxen um zahlungskräftige Kunden mit der üblichen Überbetonung technischer Dienstleistungen und den verführerischen Glücksversprechen sind Orientierungshilfen für Realisten gefragter denn je, davon ist der Spender überzeugt. Vieles bleibt offen, vielleicht sind auch Projekte preiswürdig, die Spezialisten und Grundversorger gemeinsam berücksichtigen, was dem neugeschaffenen Forschungspreis Hausarztmedizin des Kollegiums für Hausarztmedizin KHM entgegenkäme. Alfred M. Debrunner haben während seiner Berufskarriere die langfristigen Resultate immer mehr interessiert als die lukrativen Modetrends und Eintagsfliegen. So überzeugte er in den 80er Jahren die Mehrheit der Kollegen von den Vorzügen der mühsamen und kostspieligen Nachkontrolle 10 Jahre nach der Behandlung, was überraschende Einsichten mit praktischen Folgen nach sich zog.

Den Stifter könnte man auch einfach als Debrunner IV. bezeichnen. Der Urgrossvater war Allgemeinarzt in Frauenfeld, der Grossvater dort Gynäkologe, der Vater Hans Debrunner ein Pionier der schweizerischen Orthopädie, der 1937 mit einer vielbeachteten Monographie zum «an- 
geborenen Klumpfuss» habilitierte und den Boden für die spätere Universitätsklinik in Basel vorbereitete. Bekannt machten ihn seine Vorlesungen, die zahlreichen Publikationen, die neuen Operations- und Behandlungstechniken und experimentellen Untersuchungen zu angeborenen Deformitäten. Er dachte interdisziplinär und unvoreingenommen, war gerne Lehrer und schrieb mit einem sicheren Sprachstil, an dem er mit hohen Selbstansprüchen stetig feilte. Zahlreiche Briefe zeugen von seinem besonderen Interesse für die ärztliche Ethik, die Arbeit des Hausarztes und die Ausbildung der Pflegenden. Hans Debrunner, so erzählt sein Sohn, wäre gerne Schriftsteller geworden, doch er musste seiner von der Tuberkulose querschnittgelähmten Mutter versprechen, «etwas Anständiges zu lernen». Zeit seines Lebens wollte er ein umfassendes orthopädisches Lehrbuch schreiben. «Ich will versuchen, eine humane, eine menschliche Orthopädie zu schreiben und zu lehren. Nicht im technischen Spezialistentum steckenbleiben, sondern immer den leidenden Menschen zeigen», schrieb er in einem Brief 1961. Die Ironie der Familiengeschichte will es, dass sein Sohn, dessen Schreiben der Vater stets minutiös korrigierte und dem er ein Werk dieses Umfanges nicht zutraute, das Vorhaben erfolgreich ausführte. Als vom Vater testamentarisch eingesetzter Nachlassverwalter ordnet Alfred M. Debrunner die vielen Briefe und Manuskripte seines Vaters. Darunter finden sich mehrere Anläufe zu Lehrbuchtexten, auch einer in Dialogform, geschrieben im Alter von über 80 Jahren: «Briefe an einen Studenten beim Lesen von Jeremias Gotthelfs Anne Bäbi Jowäger». Ein Artikel aus Berlin von 1922 behandelt sein Steckenpferd: «Vom Stil der wissenschaftlichen Abhandlungen», in dem er mehrere medizinische Textproben zerpflückt: «Sie sollen nur helfen, die Verbreitung des Übels nachzuweisen und zu zeigen, wie hässlich eine Unachtsamkeit wirken kann, wenn wir sie aus ihrer Umgebung herausheben.» Was heute formal etwas altväterisch klingt, ist inhaltlich leider völlig zeitgemäss. Vielleicht gelang dem Sohn, was dem Vater vorbehalten blieb, weil er literarisch weniger ambitioniert ans Werk ging. Dabei hat er seinen eigenen Stil gefunden und ist heute mehr als nur der «Mittler», als der er sich bescheiden betrachtet. Nur ungern hat er sich fotografieren lassen, wollte lieber im Schatten seines Vaterbildes bleiben. Der neue Förderpreis ist im Gedenken nach Hans Debrunner benannt. Doch ohne das Talent und die selbstlose Grosszügigkeit von Alfred M., dem Vierten in der Abfolge der DebrunnerDynastie, gäbe es heute und in Zukunft einige bedeutende Brücken weniger. 